\title{
Effects of the interplanetary magnetic field $y$ component on the dayside aurora
}

\author{
K. Liou* ${ }^{*}$ and E. Mitchell
}

\begin{abstract}
A dawn-dusk asymmetry in many high-latitude ionospheric and magnetospheric phenomena, including the aurora, can be linked to the east-west (y) component of the interplanetary magnetic field (IMF). Owing to the scarcity of observations in the Southern Hemisphere, most of the previous findings are associated with the Northern Hemisphere. It has long been suspected that if the IMF $B_{y}$ component also produces a dawn-dusk asymmetry and/or a mirror image in the Southern Hemisphere as predicted by some theories. The present study explores the effect of the IMF $B_{y}$ component on the dayside aurora from both hemispheres by analyzing the auroral emission data from the Global UltraViolet scanning spectrograph Imager on board the Thermosphere lonosphere Mesosphere Energetics and Dynamics mission spacecraft from 2002 to 2007. The data set comprises 28,774 partial images of the northern hemispheric oval and 29,742 partial images of the southern hemispheric oval, allowing for a statistical analysis. It is found that even though auroras in different regions of the dayside oval respond differently to the orientation of the IMF $B_{y}$ component, their responses are opposite between the two hemispheres. For example, at 1400-1600 MLT in the Northern Hemisphere, where the so-called 1500 MLT auroral hot spots occur, peak auroral energy flux is larger for negative IMF $B_{y}$ comparing to positive IMF $B_{y}$. The response is reversed in the Southern Hemisphere. The present study also suggests that the total energy flux does not change with the IMF $B_{y}$ orientation change. This result is consistent with a larger (smaller) convection vortex in the postnoon sector for IMF $B_{y}<0\left(B_{y}>0\right)$ resulting from anti-parallel merging.
\end{abstract}

Keywords: Dayside aurora, Hemispheric asymmetry, TIMED, GUVI, FUV

\section{Introduction}

The auroral oval, when viewed from space, is a continuous ring of luminosity circling the magnetic pole and covering both nightside and dayside. Auroras that occur on dayside are considered distinct from their nightside counterpart (e.g., Akasofu and Kan 1980; Meng and Lundin 1986). The statistical precipitation energy flux into the auroral oval was first derived by Newell et al. (1996) using particle precipitation data from the Defense Meteorological Satellite Program (DMSP) satellites and later by Liou et al. (1997) using satellite imaging data in far ultraviolet (FUV) from the polar spacecraft. These studies demonstrated two local intensity maxima and one intensity minimum in the dayside auroral oval. The

\footnotetext{
*Correspondence: kan.liou@jhuapl.edu

The Johns Hopkins University Applied Physics Laboratory, 11100 Johns Hopkins Road, Laurel, MD 20723, USA
}

region near the midday is typically the weakest in auroral intensity and was named "the midday gap" (Dandekar and Pike 1978). Observations with multispectral imaging from the International Satellites for Ionospheric Studies 2 (ISIS-2) satellite suggest that the midday gap is a region of intensity minimum (Murphree et al. 1980). It features magnetosheath-like soft electron precipitation and thus is associated with the cusp (Meng 1981). A few hours east of the midday between $\sim 1400$ and 1600 MLT (magnetic local time) is a region where most intense auroral activity occurs on dayside (e.g., Cogger et al. 1977) and is often called the 1500 MLT auroral hot spot. Sometimes periodic forms of auroras appear in the afternoon sector (e.g., Lui et al. 1989). The boundary plasma sheet is found to be the major source of the brightest auroral hot spots (Liou et al. 1999). The morning warm spot, which is less intense than the 1500 MLT hot spot, is located between 0600 and 
1000 MLT and is associated with sub-keV electron precipitation (e.g., Newell et al. 1996).

The morphology of dayside auroras is believed to be controlled by the IMF orientation because solar wind energy enters the magnetosphere mainly through magnetic merging between the interplanetary magnetic field (IMF) and magnetospheric field on the dayside magnetopause. For example, the expansion and contraction of the auroral oval/polar cap are associated with the northsouth $\left(B_{z}\right.$ in Geocentric Solar Magnetospheric (GSM) coordinate) component of the IMF (e.g., Holzworth and Meng 1975) and the dawn-dusk shift of the polar cap center for different signs of IMF (Holzworth and Meng 1984). This has been interpreted by the open magnetosphere model (e.g., Cowley 1981).

In addition, the y-component of IMF may result in a hemispheric dawn-dusk asymmetry in the auroral particle precipitation. The anti-parallel merging theory (Reiff and Burch 1985) predicts the merging site in regions of highest magnetic shear at the magnetopause. As shown in Figure 1, for a southward and large positive (negative) $\mathrm{y}$-component of IMF, the merging site moves to dawn (dusk) in the Northern Hemisphere and dusk (dawn) in the Southern Hemisphere. This hemispheric dawn-dusk asymmetry in the merging site can lead to a hemispheric dawn-dusk asymmetry of the magnetospheric convection and field-aligned currents that produce a hemispheric dawn-dusk asymmetry in the dayside aurora."

The Viking FUV imaging system provided the first snapshot auroral images on global scales and led to a number of studies of dayside auroral activity in association with IMF $B_{y}$. For example, Murphree et al. (1981) reported that during non-substorm periods, discrete auroras near 1400 MLT are observed when the IMF $B_{y}$ component is often negative. Vo and Murphree (1995) found that dayside auroral hot spots observed in the Viking UV images usually in the afternoon sector occur mostly during negative IMF $B_{y}$ and have a less pronounced dependence on IMF $B_{z}$. Trondsen et al. (1999) examined auroral images from Viking UV imager observations acquired between March 1986 and November 1986 and concluded that increased dayside auroral intensity and the generation of narrow continuous auroral oval around noon are often associated with negative IMF $B_{y}$ rather than positive IMF $B_{y}$. Based on ground-based meridian scanning photometer data, Karlson et al. (1996) reported an asymmetry in the prenoon-postnoon auroral occurrence distribution caused by the IMF $B_{y}$ polarity under southward IMF conditions-auroral events predominantly occurring in the postnoon (prenoon) sector for IMF $B_{y}<0\left(B_{y}>0\right)$.

In summary, these previous studies have commonly suggested that a negative IMF $B_{y}$ component favors the occurrence of the postnoon dayside auroras. This is supported by multi-spectral observations of the dayside aurora from the ground ( $\mathrm{Hu}$ et al. 2012). They found that statistically auroral intensity at $630.0 \mathrm{~nm}$ increases monotonically with the north-south component of the solar wind electric field, with a larger (smaller) increasing rate in the postnoon than in the prenoon oval for IMF $B_{y}<0\left(B_{y}>0\right)$. However, contradictive reports exist. For example, Liou et al. (1998) analyzed the 4-month worth of global auroral images from polar and concluded that the auroral power deposited into the afternoon (13001800 MLT) sector of the northern oval is linearly proportional to the magnitude of IMF $B_{y}$ component, meaning that the magnitude of IMF $B_{y}$ is the controlling parameter. More recently, Yang et al. (2013) analyzed the same data from polar for one full year but found no significant IMF $B_{y}$ effect on the dayside auroral intensity.

If a negative IMF $B_{y}$ component favors the occurrence of postnoon auroras in the Northern Hemisphere, what would be expected for the response of the postnoon aurora to IMF $B_{y}$ in the Southern Hemisphere? This question has not been fully addressed because most of the auroral measurements come from the Northern Hemisphere. Hu et al. (2012) addressed this question by analyzing ground-based all-sky image data from both hemispheres. They found an asymmetric response of postnoon auroras at $557.7 \mathrm{~nm}$ to the IMF $B_{y}$ orientation between the two hemispheres. What is interesting in their finding is that there are significant differences between the intensity and location of the auroral enhancements from the two hemispheres in response to the sign of IMF $B_{y}$ (see Figure 2 of $\mathrm{Hu}$ et al.). It is not clear if their finding is physical and implies asymmetries in the hemispheric response to the IMF or is associated with instrumental problems, such as lack of inter-calibration of the imagers. Current understanding of the dayside merging associated with a finite IMF $B_{y}$ component predicts a dawn-dusk asymmetry, not a hemispheric asymmetry of the dayside aurora. In this study, we will look into this issue differently from space with much more data and in a more quantitative way than previous studies to clarify this puzzle (Fig. 1).

\section{Methodology}

In this study, observations of the Northern and Southern auroras from the Global Ultraviolet Imager (GUVI) (Paxton et al. 1999) on board NASA's Thermosphere, Ionosphere, Mesosphere, Energetics and Dynamics (TIMED) satellite during the period of 2002-2007 will be analyzed. The TIMED spacecraft was launched in the December of 2001 into in a near circular, Sun-synchronous orbit with an averaged altitude of $\sim 612 \mathrm{~km}$ and a $74.07^{\circ}$ inclination angle. A small $\left(\sim 3^{\circ} /\right.$ day $)$ precession of 


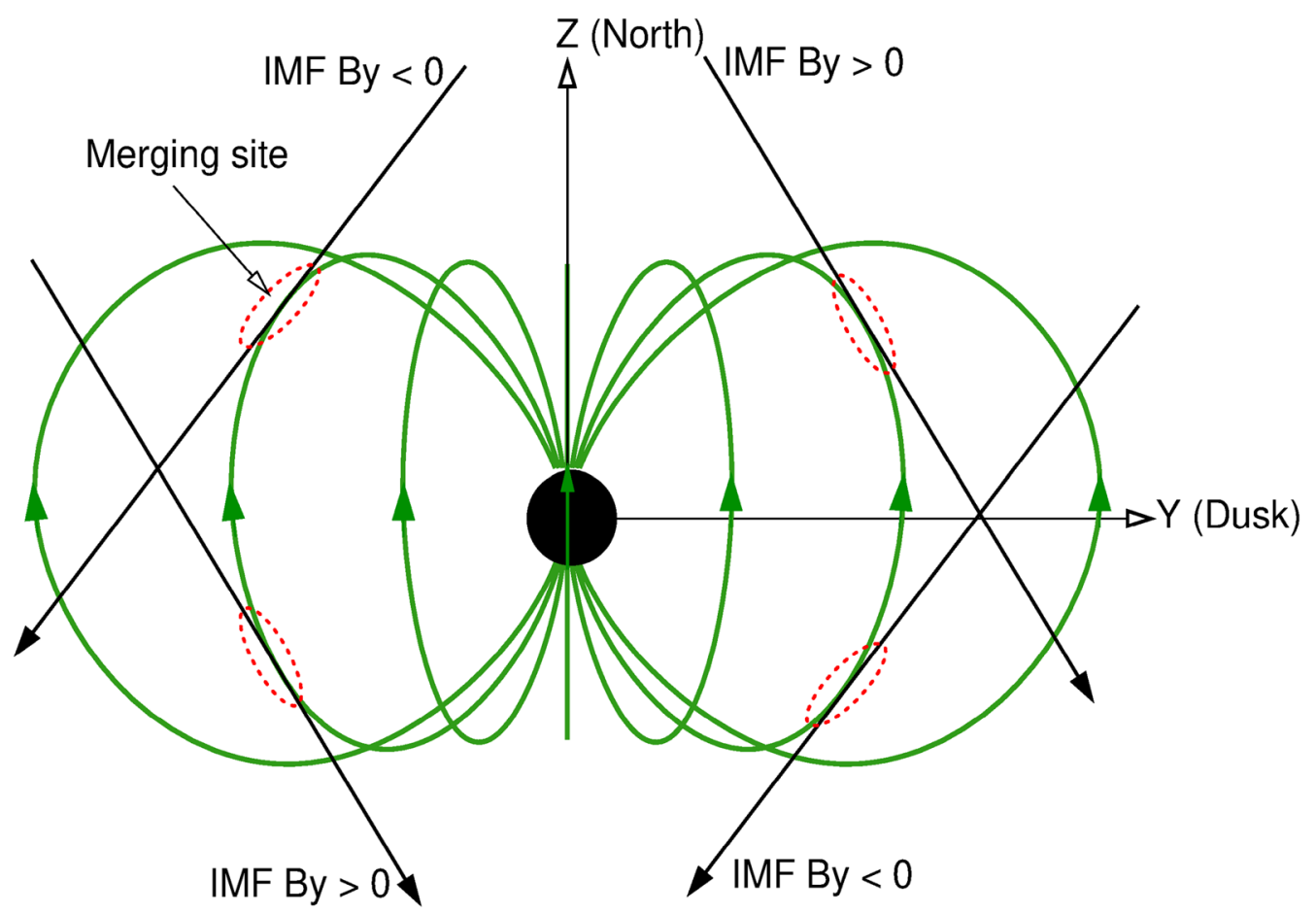

Fig. 1 Schematic drawing of magnetic field line merging between the interplanetary (black) and Earth (green) magnetic fields predicted by the anti-parallel merging model as viewed from the Sun. For a positive IMF $B_{y}$ component, the merging sites (red dashed ellipses) are located at the high-latitude dusk (dawn) sector of the Northern (Southern) Hemisphere. For a negative IMF $B_{y}$ component, the merging sites change to high-latitude dawn (dusk) sector of the Northern (Southern) Hemisphere

the TIMED spacecraft enables a full local-time coverage every 4 months. GUVI is a spectrometer in far ultraviolet (FUV) wavelengths performing limb-to-limb (cross-track) scans every $15 \mathrm{~s}$ along the satellite orbit. The field-of-view (FOV) of the GUVI is capable of producing a swath of image of $\sim 108 \mathrm{~km}$ along-track and $\sim 2500 \mathrm{~km}$ cross-track. With the nominal orbital period of $\sim 97 \mathrm{~min}$, TIMED circles the Earth $\sim 15$ times a day, which allows GUVI to cover the entire Earth, at least in the polar region, daily.

The GUVI system was operated in spectral and image modes. We will use the image mode data for the present study because of its wider spatial coverage and more abundant. In this mode, auroras were imaged in five wavelengths in the FUV spectrum, among which the Lyman-Birge-Hopfield (LBH) long band will be analyzed here. The image mode data are available from February 2002 to November 2007. A total of 27,861 and 27,633 images of Northern and Southern Hemisphere, respectively, are available for the present study. Because TIMED is a low-altitude satellite, each auroral image only covers $\sim 1 / 3$ to $\sim 1 / 2$ of the auroral oval.

We use the level-2 data of the auroral energy flux $(Q)$ inferred from the GUVI LBH-long band emission. The derivation of the energy flux, presumably all deposited by electrons, is given in detailed by Zhang and
Paxton (2008). To facilitate the analysis, the GUVI data are binned to uniform grids with $1^{\circ}$ in latitude and an equal length in longitude. The altitude adjusted corrected geomagnetic (AACGM) coordinate (Baker and Wing 1989) is used for the present analysis.

Solar wind parameters, which are based on the highresolution (1 $\mathrm{min}$ ) OMNI data provided by NASA's Space Physics Data Facility (SPDF), are used to filter the GUVI data into two categories depending on the orientation of IMF $B_{y}$. In this study, we also incorporate the solar windmagnetosphere coupling function,

$$
\mathrm{d} \phi_{\mathrm{MP}} / \mathrm{d} t=C v^{4 / 3} B_{\mathrm{t}}^{2 / 3} \sin ^{8 / 3}\left(\theta_{\mathrm{c}} / 2\right),
$$

where $v$ is the solar wind speed, $B_{\mathrm{t}}$ is the transverse to the solar wind velocity component of the IMF, $\theta_{\mathrm{c}}$ is the IMF clock angle, and $C$ is a factor) (Newell et al. 2007), to constrain the data. This coupling function has a physical meaning of the dayside merging rate and performs best among all documented in predicting the cusp latitude, which is a good proxy of the merging rate, and nine other magnetospheric state variables. The original coupling function is not normalized to units of volts (i.e., $C=1$ ). Cai and Clauer (2013) convert it to the rate of change of magnetic flux in Weber/s (or Wb/s) by substituting 
$C$ with $100 \mathrm{MWb} \mathrm{nT}{ }^{-4 / 3}(\mathrm{~km} / \mathrm{s})^{-2 / 3}$. Typically, the value of $\mathrm{d} \phi_{\mathrm{MP}} / \mathrm{d} t$ is less than $2 \mathrm{MWb} / \mathrm{s}$, with a median value $\sim 0.43 \mathrm{MWb} / \mathrm{s}$.

The idea of this study is to statistically compare auroral energy flux from the two hemispheres under "similar" solar wind driving but a different IMF $B_{y}$ orientation. Previous studies have suggested that dayside auroras are directly driven (e.g., Liou et al. 1998). To make the comparison under similar solar wind driving, we require the "instantaneous" (after 10-min delay and averaged over $5 \mathrm{~min}$ ) value of $\mathrm{d} \phi_{\mathrm{MP}} / \mathrm{d} t$ to be greater than 0.2 but less than $2 \mathrm{MWb} / \mathrm{s}$. We also require a small value of the timeweighted coupling function, $\mathrm{d} \phi_{\mathrm{MP}}^{\mathrm{W}} / \mathrm{d} t<0.2 \mathrm{MWb} / \mathrm{s}$ to minimize the effect of nightside aurora that may expand to dayside during geomagnetic periods (e.g., Murphree et al. 1981). The time-weighted coupling function is based on 4-h solar wind data and is weighted by the factor of $(2 / 3)^{n}$, where $n$ is the hour number from the current time (Newell et al. 2007). Since dayside auroras are also affected by solar illumination (e.g., Liou et al. 1998) and season (e.g., Liou et al. 2001), we use the solar zenith angle (SZA), the angle between the local zenith and the direction of the Sun, to separate the data into dark $\left(\mathrm{SZA}>108^{\circ}\right)$ and sunlit $\left(\mathrm{SZA}<108^{\circ}\right)$ categories. Comparing the aurora data under the dark condition should eliminate the solar illumination effect. Figure 2 shows histograms of the coupling function for (a) IMF $B_{y}>2 \mathrm{nT}$ and (b) IMF $B_{y}<-2 \mathrm{nT}$ for Northern (blue traces) and Southern (red traces) hemispheric events. It is shown that under the criteria mentioned above, all four histograms are nearly identical. The averaged (median) value for the Northern and Southern hemispheric events is
$0.508 \mathrm{~Wb} / \mathrm{s}(0.380 \mathrm{~Wb} / \mathrm{s})$ and $0.505 \mathrm{~Wb} / \mathrm{s}(0.374 \mathrm{~Wb} / \mathrm{s})$ for IMF $B_{y}>2 \mathrm{nT}$, respectively, and $0.500 \mathrm{~Wb} / \mathrm{s}$ $(0.378 \mathrm{~Wb} / \mathrm{s})$ and $0.503 \mathrm{~Wb} / \mathrm{s}(0.388 \mathrm{~Wb} / \mathrm{s})$ for IMF $B_{y}<-2 \mathrm{nT}$, respectively. Therefore, it is expected that any difference between the two data sets must be associated with the orientation of IMF $B_{y}$.

\section{Results}

Figure 3 compares the dayside auroral energy flux for positive $(>2 \mathrm{nT})$ and negative $(<-2 \mathrm{nT})$ IMF $B_{y}$ for the Northern and Southern Hemispheres under solar wind driving $\left(\mathrm{d} \phi_{\mathrm{MP}} / \mathrm{d} t>0.2 \mathrm{MWb} / \mathrm{s}\right.$ and $\mathrm{d} \phi_{\mathrm{MP}}^{\mathrm{W}} / \mathrm{d} t<0.2 \mathrm{MWb} / \mathrm{s}$ ) and ionospheric dark conditions. In the $\mathrm{NH}$ (left column), the afternoon/auroral energy flux is limited within a narrow $\left(\sim 5^{\circ}\right)$ band of the oval. It is slightly larger for negative than positive IMF $B_{y}$. The enhancement occurs mainly in the 1400-1600 MLT sector. On the other hand, the trend is reversed in the $\mathrm{SH}$ (right column), where the afternoon auroral energy flux is larger for positive than negative IMF $B_{y}$. For a fixed IMF $B_{y}$ polarity the auroral energy flux in the afternoon sector is larger in the $\mathrm{SH}(\mathrm{NH})$ for positive (negative) IMF $B_{y}$. This comparison suggests that negative IMF $B_{y}$ favors Northern hemispheric auroras, as reported previously (Murphree et al. 1981; Vo and Murphree 1995; Trondsen et al. 1999), and a positive IMF $B_{y}$ favors the Southern hemispheric aurora, resulting in a north-south asymmetry in the response of the afternoon aurora to IMF $B_{y}$ orientation. Note that such a result can never appear at the same time because both hemispheres cannot be dark at the same time.
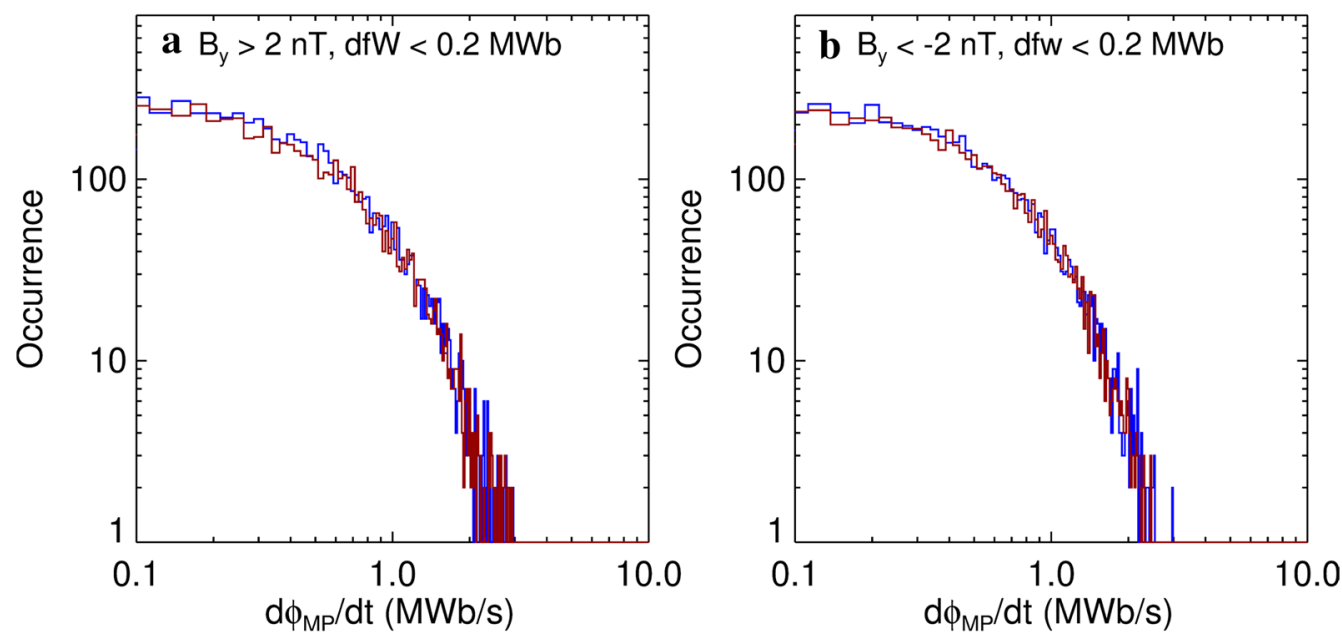

Fig. 2 Histogram of the coupling function, $d \phi_{M P} / d t$, for $\mathbf{a} I M F B_{y}>2 n T$ and $\mathbf{b} I M F B_{y}<-2 n T$. In each panel, the blue trace is for the Northern hemispheric events, whereas the red trace is for the Southern hemispheric events. The time-weighted coupling function, $\mathrm{d} \phi_{\mathrm{MP}}^{\mathrm{W}} / \mathrm{d} t$, for both cases is limited within $0.2 \mathrm{MWb} / \mathrm{s}$ (see text for details) 

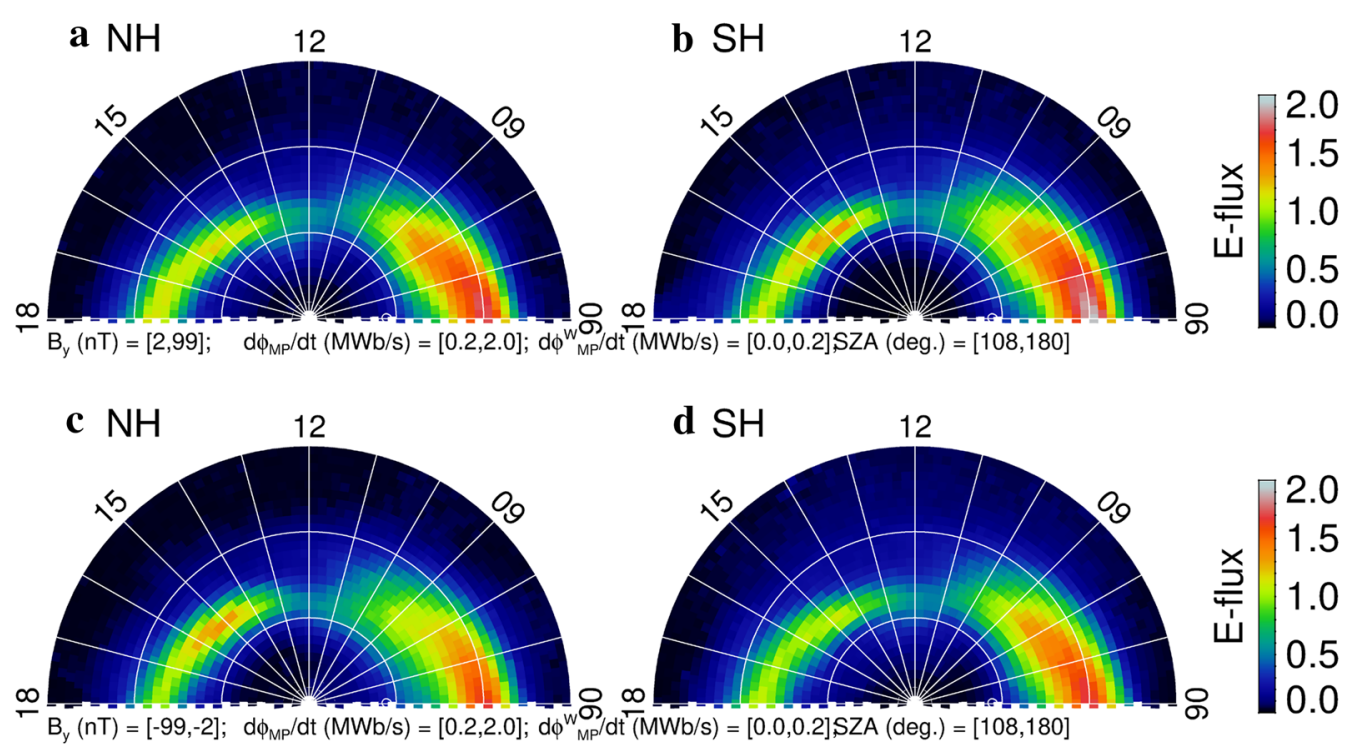

Fig. 3 Averaged electron energy flux (in erg $/ \mathrm{cm}^{2}-$ s) deposited into the dark (solar zenith angle: $\mathrm{SZA}>108^{\circ}$ ) a Northern Hemisphere (NH) and the dark b Southern Hemisphere (SH) for positive IMF $B_{y}(>2 \mathrm{nT})$. c, d Are in the same format as (a) and (b) but for negative IMF $B_{y}(<-2 \mathrm{nT})$
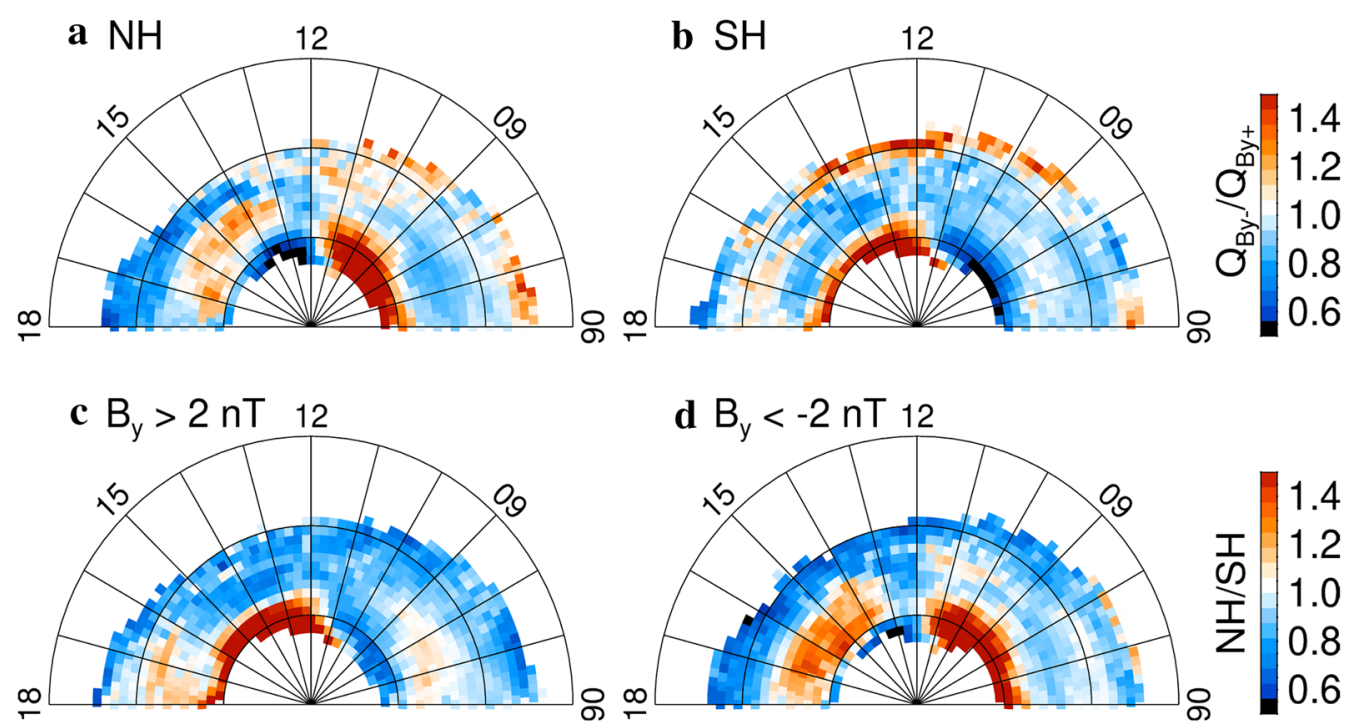

Fig. 4 The ratio of dayside hemispheric auroral energy flux associated with negative $\left(Q_{B_{y}}\right)$ and positive $\left(Q_{B_{y+}}\right) I M F B_{y}$ components for the a $N H$ and the $\mathbf{b} \mathrm{SH} . \mathbf{c}, \mathbf{d}$ Are the ratio of dayside hemispheric auroral power between the $\mathrm{NH}$ and the SH for positive and negative IMF $B_{y}$, respectively

The auroral energy flux in the prenoon sector covers a wider $\left(\sim 10^{\circ}\right)$ latitude than does the postnoon counterpart, and is not isolated from the nightside aurora (not shown). This region of the oval is on the drift path of earthward convecting electrons from the central plasma sheet. Auroral precipitation is dominantly of diffuse type and is closely related to nightside activity. Overall, the prenoon auroral energy flux is slightly larger for positive IMF $B_{y}$ for both hemispheres and is larger in SH than in NS regardless of the IMF $B_{y}$ polarity. There is evidence that the westward auroral electrojet is more intense for positive than negative IMF $B_{y}$ (e.g., Laundal et al. 2016; Friis-Christensen et al. 2017). We do not know if this is also true for diffuse aurora, although it is tempting to speculate that the two are related. It deserves a separate study from the present one. 
We plot the ratio of the dayside auroral energy flux $\left(>0.1 \mathrm{erg} / \mathrm{cm}^{2}-\mathrm{s}\right)$ between the two hemispheres and between two different IMF $B_{y}$ polarities in Fig. 4 for an easy comparison. As shown in Fig. 4, the hemispheric asymmetry in the auroral response to the IMF $B_{y}$ orientation is clearly shown, as well as the dawn-dusk asymmetry in both hemispheres associated with the IMF $B_{y}$ polarity. Figure $4 \mathrm{a}$, b shows the energy flux ratio under negative IMF $B_{y}$ relative to positive IMF $B_{y}$ for Northern and Southern Hemisphere, respectively. Notice the highdegree of similarity between the two maps (the colors are reversed). A few significant features are worth mentioning. At high latitudes ( $>\sim 78^{\circ}$ MLAT) next to the polar cap, a negative IMF $B_{y}$ component favors the Northern hemispheric prenoon and the Southern hemispheric postnoon sectors. At lower latitudes $\left(\sim 74^{\circ}-78^{\circ} \mathrm{MLAT}\right)$, where energy flux is the largest, a negative IMF $B_{y}$ component favors the Northern hemispheric postnoon, and to a much weaker extent, the Southern hemispheric prenoon sectors. Near the equatorward edge of the oval, a negative (positive) IMF $B_{y}$ component favors the Southern (Northern) hemispheric dusk sector. Figure 4c, d shows the comparison of energy flux between the Northern and Southern Hemisphere for positive and negative IMF $B_{y}$, respectively. Under positive IMF $B_{y}$ conditions, the energy flux is larger in the Northern Hemisphere than in the Southern Hemisphere in the afternoon high-latitude ( $>\sim 78^{\circ}$ MLAT) and prenoon mid-latitude (between $70^{\circ}$ and $80^{\circ} \mathrm{MLAT}$ ) regions and it is larger in the Southern Hemisphere than in the Northern Hemisphere in
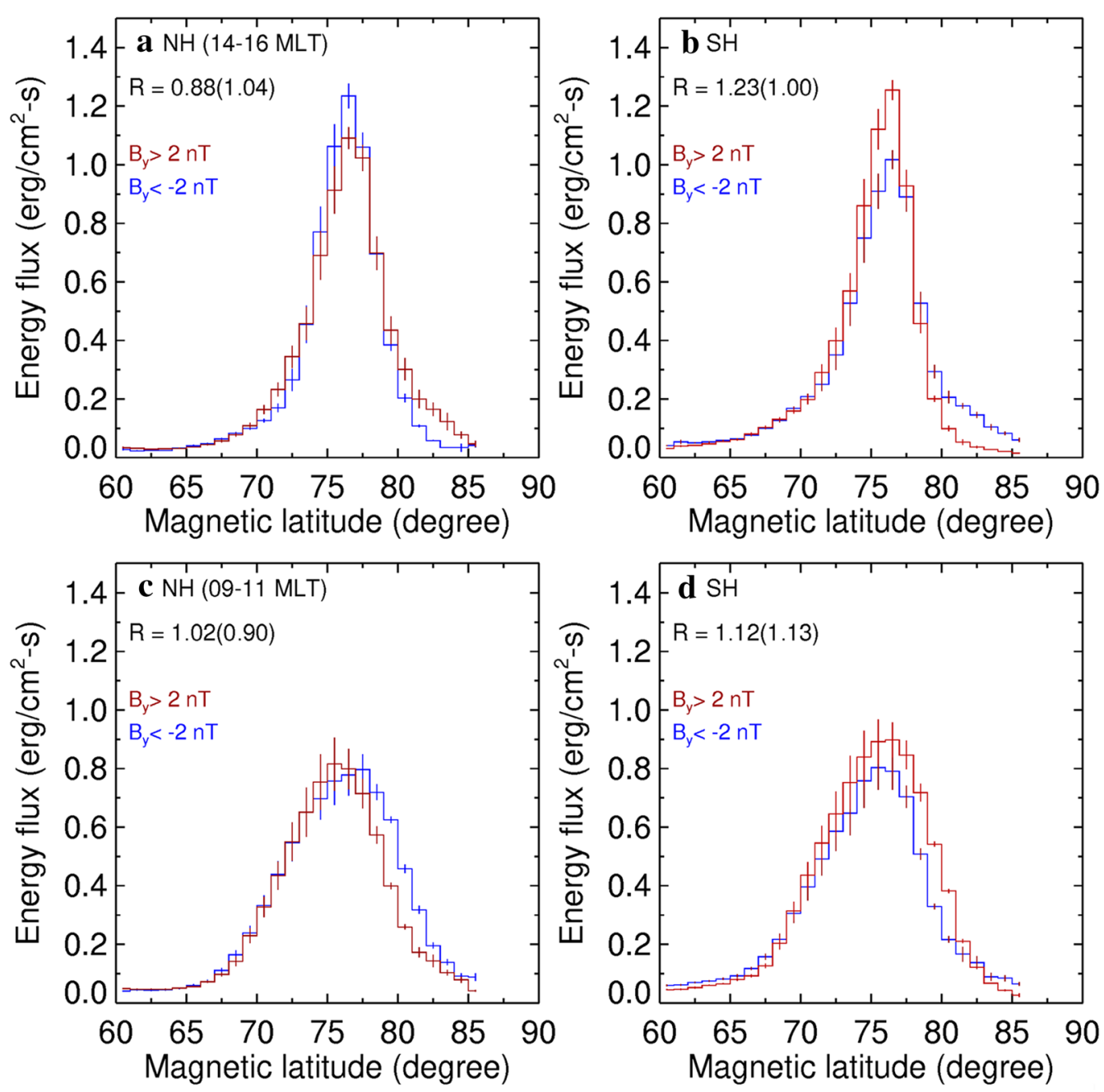

Fig. 5 Latitudinal profiles of auroral energy flux averaged over the 1400-1600 MLT sector for the a Northern and $\mathbf{b}$ Southern Hemispheres. In each panel the red trace is for IMF $B_{y}>2 \mathrm{nT}$ and the blue trace is for IMF $B_{y}<-2 \mathrm{nT}$. The vertical line segments are one standard deviation of the sample means. $\mathbf{c}, \mathbf{d}$ Are in the same format as $(\mathbf{a}, \mathbf{b})$ but for the prenoon 0900-1100 MLT sector. The insert values $R$ is the red-to-blue energy flux ratio at the flux peak and, in the parenthesis, integrated over the latitude 
the prenoon high-latitude and postnoon mid-latitude regions. Under negative IMF $B_{y}$ conditions, the trend is reversed.

To make the comparison more quantitatively, Fig. 5 shows latitudinal profiles of energy flux averaged over the 1400-1600 MLT and 0900-1100 MLT sector for Northern and Southern Hemispheres. In the Northern Hemisphere (Fig. 5a), a negative IMF $B_{y}$ is associated with a larger $(\sim 11 \%)$ energy flux at the flux peak but smaller energy flux at higher latitudes. In the Southern Hemisphere (Fig. 5b), it is reversed-a positive IMF $B_{y}$ is associated with a larger $(\sim 23 \%)$ energy flux at the flux peak but smaller energy flux at higher latitudes. A close observation suggests that the total energy (integrated over the latitudes) shows little change in response to the IMF $B_{y}$ orientation-the ratio is 1.04 and 1.00 for the Northern and Hemisphere, respectively. In the prenoon 0900-1100 MLT sector, there is no clear trend for the peak flux. However, in the Northern Hemisphere, a wider oval is found to be associated with negative IMF $B_{y}$ than with a positive IMF $B_{y}$. This dependency is reversed in the Southern Hemisphere. A closer observation indicates that the wider oval is due mainly to the expansion of the oval toward higher latitudes.

\section{Discussion}

We have explored the long standing question about effects of IMF $B_{y}$ orientation on the morphology of the dayside aurora for the Northern and Southern Hemispheres. It is shown, under similar solar wind driving, the postnoon auroral hot spot, which is centered at 1500 MLT in the Northern Hemisphere (Newell et al. 1996; Liou et al. 1997), also exist in the Southern Hemisphere and at the same local time. It is also found that in the postnoon 1400-1600 MLT sector of the Northern Hemisphere, the peak auroral energy flux is larger $(\sim 11 \%)$ for negative IMF $B_{y}$ than for positive IMF $B_{y}$. The postnoon aurora can reach higher latitudes for positive IMF $B_{y}$ compared to negative IMF $B_{y}$, resulting in larger energy flux there for positive than negative IMF $B_{y}$. This IMF $B_{y}$ polarity dependence for the postnoon aurora is reversed and more pronounced in the Southern Hemisphere-the peak auroral energy flux is larger ( 23\%) for positive than negative IMF which are also present asymmetric $_{y}$. In the prenoon sector, the auroral response to the IMF $B_{y}$ orientation is in general opposite to that of the postnoon aurora but less pronounced. This result suggests an asymmetrical response of the aurora in the dawn and dusk sectors to the orientation of IMF $B_{y}$.

The present result that a clear IMF $B_{y}$ effect on the postnoon aurora and a weaker IMF $B_{y}$ effect on the prenoon aurora is consistent with the recent finding that upward field-aligned currents are well correlated with auroral precipitation in the dusk sector, but not in the dawn sector (Korth et al. 2014). The present finding is, to a certain extent, also consistent with the reports that negative IMF $B_{y}$ favors the occurrence of auroras in the afternoon sector (e.g., Murphree et al. 1981; Vo and Murphree 1995; Trondsen et al. 1999). One must note that these studies are qualitative and therefore cannot address the absolute intensity of the aurora. These authors have associated their findings to the field-aligned currents and ionospheric convection, which also appear to response asymmetrically to the orientation of the IMF $B_{y}$ component (e.g., Burch et al. 1985). The present finding of the lack of dependence of the total auroral energy flux deposited in the postnoon sector $(1400-1600)$ on the IMF $B_{y}$ orientation is consistent with the finding reported by Liou et al. (1998), who found the total auroral power in the afternoon (1300-1800 MLT) is linearly proportional to the magnitude of IMF $B_{y}$. This can also explain why Yang et al. (2013) did not find a dependency of the afternoon auroral intensity on the orientation of IMF $B_{y}$ component. Based on the present and these previous results, the orientation of IMF $B_{y}$ does not lead to more energy precipitation in the postnoon sector but affects the precipitation pattern in the ionosphere. In the Northern (Southern) Hemisphere, a negative (positive) $B_{y}$ component changes the precipitation pattern such that the postnoon is more focused and brighter. This is the reason why previous studies often found enhanced auroral intensity in the Northern Hemisphere during IMF $B_{y}<0$.

The topology change of the magnetosphere is an important manifestation of solar wind-magnetosphere coupling, and magnetic field merging/reconnection plays the key role in the coupling. The anti-parallel merging model (Reiff and Burch 1985) predicts two merging sites in opposite side of the noon in each hemisphere for a finite IMF $B_{y}$ component. It is generally believed that this north-south asymmetry in the merging sites, when coupled with the solar wind drag, is responsible for the dawn-dusk asymmetry in the ionospheric plasma convection (e.g., Ruohoniemi and Greenwald 1996), fieldaligned currents (e.g., Burch et al. 1985; Weimer 2001), and perhaps dayside auroras (e.g., Murphree et al. 1981).

Postnoon auroras are collocated with the upward region-1 field-aligned currents (Iijima and Potemra 1976). Enhanced dayside auroral arcs are associated with enhanced upward field-aligned currents and a strong convection reversal in the ionosphere. Plasma convection in the ionosphere can generate field-aligned currents (e.g., Sato and Iijima 1979) proportional to the flow vorticity $(\omega=\Delta \times \boldsymbol{v})$, which is largest at the flow reversal $(\boldsymbol{\omega} \sim v / r)$ for a solid body rotation. In the Northern Hemisphere, the duskside convection cell reversal is found to be crescent in shape for IMF $B_{y}<0$ and rounded for 

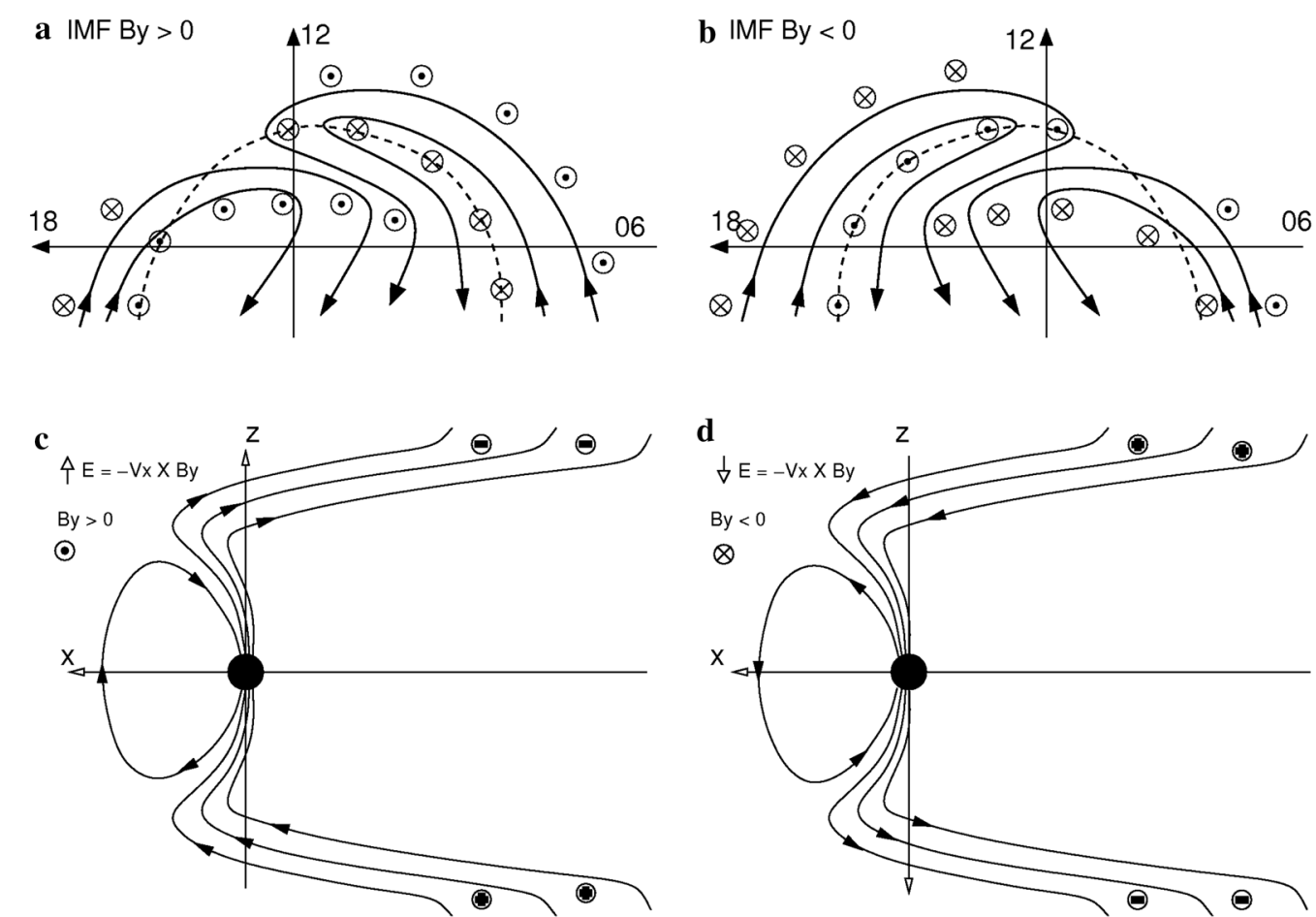

Fig. 6 Schematic drawing of the ionospheric plasma flows associated with a interplanetary magnetic field (IMF) $B_{y}>0$ and $\mathbf{b}$ IMF $B_{y}<0$ (based on Cowley et al. (1991)). The dashed line in each panel delineates the open-closed magnetic flux boundary and the circled symbols represent the field-aligned current flows (upward for circles with a dot and downward for circles with a cross). The bottom row shows the field-aligned current system associated with $\mathbf{c} I M F B_{y}>0$ and $\mathbf{d}$ IMF $B_{y}<0$ (based on Trondsen et al. 1999). The IMF $B_{y}$ field produces a north-south potential drop across the magnetotail that drives field-aligned currents northward or southward depending on the orientation of IMF $B_{y}$

IMF $B_{y}>0$ (Ruohoniemi and Greenwald 1996), and the reverse is true for the convection cell in the dawn sector. The convection flow pattern is reversed in response to the reversal of IMF $B_{y}$ in the Southern Hemisphere (e.g., Förster and Haaland 2015). A schematic drawing of the ionospheric plasma convection and field-aligned currents in the Northern Hemisphere associated with IMF $B_{y}>0$ and IMF $B_{y}<0$ is given in Fig. 6. In the dusk sector, a larger flow shear for IMF $B_{y}<0$ than for IMF $B_{y}>0$ can produce a larger upward field-aligned current and more intense auroral precipitation there. In the dawn sector, a larger field-aligned current associated with a larger flow shear for IMF $B_{y}>0$ than for IMF $B_{y}<0$ is expected. However, the field-aligned current is downward and is not associated with electron precipitation. The present result supports the above description of the convection flow and field-aligned currents in response to the orientation of IMF $B_{y}$.

In the dawn sector, however, the present result does not support the convection model, which predicts little influence in the dawn sector because the region-1 fieldaligned current is dawnward and is not associated with particle precipitation. While diffuse auroras dominate the dawn sector particle precipitation because nightside electrons drift dawnward, auroral arcs can also appear, thought less frequent and intense, in the dawn sector (e.g., Newell et al. 1996). It is possible that field-aligned currents associated with auroral arcs in the dawn sector also enhanced in response to a stronger convection for IMF $B_{y}>0$. However, we are not aware of any report about field-aligned current enhancements associated with the orientation of IMF $B_{y}$.

The convection model may explain the expansion of the postnoon aurora to higher latitudes for positive IMF $B_{y}$. When IMF $B_{y}$ is positive, the larger dusk cell can expand to high latitudes, as well as its associated field-aligned currents, as shown in Fig. 6a. Electron precipitation associated with the field-aligned currents can produce auroras, probably weak, at higher latitudes. A little change in the prenoon aurora is expected because the field-aligned currents are dawnward. This is not consistent with our observations, which show an opposite response comparing to the postnoon aurora. On the other hand, it has been reported that the center of the Southern polar cap, when fitted with a circle, shifts duskward when IMF $B_{y}>0$ and dawnward when IMF $B_{y}<0$ (Holzworth and 
Meng 1984). This is consistent with our result shown in Fig. 5b, d. Dayside anti-parallel magnetic field merging can occur in the high-latitude afternoon magnetopause for IMF $B_{y}>0$ and high-latitude prenoon for IMF $B_{y}>0$. Open magnetic fluxes are pulled into the lobe from dayside, through the noon-midnight meridian, to the nightside of opposite quadrant due to the magnetic tension force. This effect is opposite between the two hemispheres. Therefore, it is expected that the Northern oval moves dawnward for IMF $B_{y}>0$ and duskward for IMF $B_{y}<0$, as shown in Fig. $5 \mathrm{a}$, b.

The present result of a hemispheric asymmetry in the dayside aurora may also suggest existence of an interhemispheric current associated with a finite IMF $B_{y}$ component, in addition to the large-scale region-1 and region-2 currents systems responsible for steady-state convection. A field-aligned current system associated with the IMF $B_{y}$ component has been theoretically considered (e.g., Leontyev and Lyatsky 1974). According to this model, the solar wind motional electric field, after reconnection, polarizes the polar cap (open flux) region with opposite charges, depending on the orientation of IMF $B_{y}$, setting up field-aligned currents. The field-aligned currents can flow in the ionosphere into low latitudes and form a thin layer of interhemispheric field-aligned currents in the close region (Kozlovsky et al. 2003). A schematic drawing of this model is shown in the bottom panels of Fig. 6. As shown in Fig. 6c, a positive IMF $B_{y}$ component will induce an interhemispheric field-aligned current out of the Southern Hemisphere, whereas a negative IMF $B_{y}$ component will induce an interhemispheric field-aligned current out of the Northern Hemisphere. The IMF $B_{y^{-}}$ induced interhemispheric field-aligned current implies a larger (weaker) auroral intensity in the hemisphere where currents are flowing out. Therefore, this model predicts that dayside auroras are more intense in the Northern Hemisphere for IMF $B_{y}<0$ and in the Southern Hemisphere for IMF $B_{y}>0$. The present analysis result clearly indicates that the condition is more completed. Since this model applies perhaps only to regions close to the openclosed boundary, Fig. 5a, b indicates that the model correctly predicts the dawn sector but not the dusk sector for both hemispheres.

Finally, the present finding provides an impact in space weather forecasting. With simplicity in mind, current auroral models are parameterized by the Kp index (Hardy et al. 1991) or the solar wind coupling function (Newell et al. 2014). These models are not capable of simulating the IMF $B_{y}$ effect as presented here because both parameters are not taking the IMF $B_{y}$ orientation into consideration. Second, these models assumed symmetric auroral ovals and were constructed using combined data from both hemispheres. This assumption is clearly not valid as it is clearly shown in the present result. Future work on improvements of these models based on the present result is crucial for accurate aurora forecasting.

\section{Conclusions}

We have performed a statistical analysis of the auroral images in FUV acquired by the TIMED/GUVI spectrograph imager under dark conditions. Surprisingly, the socalled 1500 MLT auroral hot spot also exists in Southern Hemisphere and at exactly the same local time. It is also found that the IMF $B_{y}$ orientation plays an important role in the dayside auroral morphology. A few salient findings are listed below: (a) The energy flux in the postnoon sector becomes more focused and the peak value is $\sim 11 \%$ (23\%) larger in the Northern (Southern) Hemisphere for negative (positive) than for positive (negative) IMF $B_{y}$, but the total intensity does not change with the IMF $B_{y}$ orientation; (b) A weaker response to the IMF $B_{y}$ orientation is found for the prenoon aurora, which shows an opposite response to the IMF $B_{y}$ orientation comparing to the postnoon aurora; (c) The asymmetric response of dayside auroras to the IMF $B_{y}$ orientation is expected to form a north-south asymmetry in the dayside aurora, especially in the postnoon sector. Part of the present finding can be explained by the ionospheric convection flow model.

\section{Abbreviations \\ AACGM: altitude adjusted corrected geomagnetic; IMF: interplanetary magnetic field; ISIS: International Satellites for Ionospheric Studies; FUV: far ultraviolet; GUVI: Global Ultraviolet Imager; LBH: Lyman-Birge-Hopfield; MLT: magnetic local time; MLAT: magnetic latitude; NH: Northern Hemisphere; SPDF: Space Physics Data Facility; SH: Southern Hemisphere; SZA: solar zenith angle; TIMED: Thermosphere lonosphere Mesosphere Energetics and Dynamics.}

\section{Acknowledgements}

The GUVI instrument was designed and built by The Aerospace Corporation and the Johns Hopkins University. The Principal Investigator is Andre B. Christensen and the Co-PI is Larry J. Paxton. The GUVI data reported herein are available through the TIMED/GUVI website at http://guvitimed.jhuapl.edu. The 1-min IMF and solar wind data were provided through OMNIWeb by the Space Physics Data Facility (SPDF) (ftp://spdf.gsfc.nasa.gov/pub/data/omni/ highresomni/).

\section{Authors' contributions}

All authors worked on the project and wrote the final manuscript. Both authors read and approved the final manuscript.

\section{Funding}

This study was supported by the NSF (\# 1743118) and AFOSR (\# 26-0201-5162) Grants to the Johns Hopkins University Applied Physics Laboratory.

\section{Availability of data and materials}

The datasets, e.g., auroral images and solar wind data, analyzed during this study is available from the GUVI website (http://guvitimed.jhuapl.edu) and from NASA's SPDF website (https://spdf.gsfc.nasa.gov/), respectively.

Competing interests

The authors declare that they have no competing interests. 
Received: 6 September 2019 Accepted: 25 October 2019

Published online: 08 November 2019

\section{References}

Akasofu S, Kan JR (1980) Dayside and nightside auroral arc systems. Geophys Res Lett 7:753-756

Baker KB, Wing S (1989) A new magnetic coordinate system for conjugate studies at high latitudes. J Geophys Res 94:9139-9143

Burch JL, Reiff PH, Menietti JD, Heelis RA, Hanson WB, Shawhan SD, Shelley EG, Sugiura M, Weimer DR, Winningham JD (1985) IMF By dependent plasma flow and Birkeland currents in the dayside magnetosphere: 1. Dynamics explorer observations. J Geophys Res 90:1577-1593

Cai X, Clauer CR (2013) Magnetospheric sawtooth events during the solar cycle 23. J Geophys Res Space Phys 118:6378-6388

Cogger LL, Murphree JS, Ismail S, Anger CD (1977) Characteristics of dayside

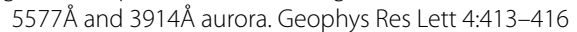

Cowley SWH (1981) Magnetospheric asymmetries associated with the Y component of the IMF. Planet Space Sci 29:79

Dandekar BS, Pike CP (1978) The midday, discrete auroral gap. J Geophys Res 83:4227-4236

Förster M, Haaland S (2015) Interhemispheric differences in ionospheric convection: cluster EDI observations revisited. J Geophys Res Space Phys 120:5805-5823. https://doi.org/10.1002/2014JA020774

Friis Christensen E, Finlay CC, Hesse M, Laundal KM (2017) Magnetic field perturbations from currents in the dark polar regions during quiet geomagnetic conditions. Space Sci Rev 206:281-297. https://doi.org/10.1007/ s11214-017-0332-1

Hardy DA, McNeil W, Gussenhoven MS, Brautigam D (1991) A statistical model of auroral ion precipitation: 2. Functional representation of the average patterns. J Geophys Res 96:5539-5547. https://doi.org/10.1029/90JA0 2451

Holzworth RH, Meng C (1975) Mathematical representation of the auroral oval. Geophys Res Lett 2:377-380. https://doi.org/10.1029/GL002i009p00377

Holzworth RH, Meng C-I (1984) Auroral boundary variations and the interplanetary magnetic field. Planet Space Sci 32:25-29. https://doi. org/10.1016/0032-0633(84)90038-2

Hu ZJ, Yang HG, Han DS, Huang DH, Zhang BC, Hu HQ, Liu RY (2012) Dayside auroral emissions controlled by IMF: a survey for dayside auroral excitation at 557.7 and $630.0 \mathrm{~nm}$ in Ny Ålesund, Svalbard. J Geophys Res 117:A02201. https://doi.org/10.1029/2011ja017188

lijima T, Potemra TA (1976) The amplitude distribution of field-aligned currents at Northern high latitudes observed by Triad. J Geophys Res 81:21652174. https://doi.org/10.1029/JA081i013p02165

Karlson KA, Øieroset M, Moen J, Sandholt PE (1996) A statistical study of flux transfer event signatures in the dayside aurora: the IMF By related prenoon postnoon symmetry. J Geophys Res 101:59-68. https://doi. org/10.1029/95JA02590

Korth H, Zhang Y, Anderson BJ, Sotirelis T, Waters CL (2014) Statistical relationship between large scale upward field-aligned currents and electron precipitation. J Geophys Res Space Phys 119:6715-6731. https://doi. org/10.1002/2014JA019961

Kozlovsky A, Turunen T, Koustov A, Parks G (2003) IMF B effects in the magnetospheric convection on closed magnetic field lines. Geophys Res Lett 30(24):2261. https://doi.org/10.1029/2003GL018457

Laundal KM, Gjerloev JW, Ostgaard N, Reistad JP, Haaland S, Snekvik K, Tenfjord P, Ohtani S, Milan SE (2016) The impact of sunlight on high latitude equivalent currents. J Geophys Res Space Phys 121:2715-2726. https:// doi.org/10.1002/2015JA022236

Leontyev SV, Lyatsky WB (1974) Electric field and currents connected with y-component of interplanetary magnetic field. Planet Space Sci 22:811-819. https://doi.org/10.1016/0032-0633(74)90151-2

Liou K, Newell PT, Meng Cl, Brittnacher M, Parks G (1997) Synoptic auroral distribution: a survey using Polar ultraviolet imagery. J Geophys Res 102:27197-27205. https://doi.org/10.1029/97JA02638

Liou K, Newell PT, Meng C-I, Brittnacher M, Parks G (1998) Characteristics of the solar wind controlled auroral emissions. J Geophys Res 103:17543-17557. https://doi.org/10.1029/98ja01388
Liou K, Newell PT, Meng C-I, Sotirelis T, Brittnacher M, Parks G (1999) Source region of 1500 MLT auroral bright spots: simultaneous Polar UV images and DMSP particle data. J Geophys Res 104:24587-24602. https://doi. org/10.1029/1999JA900290

Liou K, Newell PT, Meng C-I (2001) Seasonal effects on auroral particle acceleration and precipitation. J Geophys Res 106(A4):5531-5542. https://doi. org/10.1029/1999JA000391

Lui ATY, Venkatesan D, Murphree JS (1989) Auroral bright spots on the dayside oval. J Geophys Res 94:5515-5522. https://doi.org/10.1029/JA094iA05p 05515

Meng Cl (1981) Electron precipitation in the midday auroral oval. J Geophys Res 86:2149-2174. https://doi.org/10.1029/JA086iA04p02149

Meng Cl, Lundin R (1986) Auroral morphology of the midday oval. J Geophys Res 91:1572-1584. https://doi.org/10.1029/JA091iA02p01572

Murphree JS, Cogger LL, Anger CD, Ismail S, Shepherd GG (1980) Large scale $6300 \AA, 5577 \AA$, $3914 \AA$ dayside auroral morphology. Geophys Res Lett 7:239-242. https://doi.org/10.1029/GL007i004p00239

Murphree JS, Cogger LL, Anger CD (1981) Characteristics of the instantaneous auroral oval in the 1200-1800 MLT sector. J Geophys Res 86:7657-7668. https://doi.org/10.1029/JA086iA09p07657

Newell PT, Lyons KM, Meng CI (1996) A large survey of electron acceleration events. J Geophys Res 101:2599-2614. https://doi.org/10.1029/95JA0 3147

Newell PT, Sotirelis T, Liou K, Meng C-I, Rich FJ (2007) A nearly universal solar wind-magnetosphere coupling function inferred from 10 magnetospheric state variables. J Geophys Res 112:A01206. https://doi. org/10.1029/2006JA012015

Newell PT, Liou K, Zhang Y, Sotirelis T, Paxton LJ, Mitchell EJ (2014) OVATION Prime-2013: extension of auroral precipitation model to higher disturbance levels. Space Weather 12:368-379. https://doi.org/10.1002/2014S W001056

Paxton LJ, et al (1999) Global ultraviolet imager (GUVI): measuring composition and energy inputs for the NASA thermosphere ionosphere mesosphere energetics and dynamics (TIMED) mission, in optical spectroscopic techniques and instrumentation for atmospheric and space research III. In: Larar AM (ed) Proceedings of SPIE, vol 3756, pp 256-276

Reiff PH, Burch JL (1985) By-dependent dayside plasma flow and Birkeland currents in the dayside magnetosphere, 2, a global model for northward and southward IMF. J Geophys Res 90:1595-1609

Ruohoniemi JM, Greenwald RA (1996) Statistical patterns of high latitude convection obtained from Goose Bay HF radar observations. J Geophys Res 101:21743-21763. https://doi.org/10.1029/96JA01584

Sato T, lijima T (1979) Primary sources of large scale Birkeland currents. Space Sci Rev 24:347-366. https://doi.org/10.1007/BF00212423

Trondsen TS, Lyatsky W, Cogger LL, Murphree JS (1999) Interplanetary magnetic field By control of dayside auroras. J Atmos Sol-Terr Phys 61:829840. https://doi.org/10.1016/S1364-6826(99)00029-2

Vo HB, Murphree JS (1995) A study of dayside auroral bright spots seen by the Viking Auroral Imager. J Geophys Res 100(A3):3649-3655. https://doi. org/10.1029/94JA03138

Weimer DR (2001) Maps of ionospheric field-aligned currents as a function of the interplanetary magnetic field derived from Dynamics Explorer 2 data. J Geophys Res 106:12889-12902. https://doi.org/10.1029/2000JA000295

Yang YF, Lu JY, Wang JS, Peng Z, Zhou L (2013) Influence of interplanetary magnetic field and solar wind on auroral brightness in different regions. J Geophys Res Space Phys 118:209-217. https://doi.org/10.1029/2012J A017727

Zhang Y, Paxton LJ (2008) An empirical Kp-dependent global auroral model based on TIMED/GUVI FUV data. J Atmos Sol Terr Phys 70:1231-1242. https://doi.org/10.1016/j.jastp.2008.03.008

Cowley SWH, Morelli JP, Lockwood M (1991) Dependence of convective flows and particle precipitation in the high-latitude dayside ionosphere on the $X$ and $Y$ components of the interplanetary magnetic field. J Geophys Res 96(A4): 5557-5564. https://doi.org/10.1029/90JA02063

\section{Publisher's Note}

Springer Nature remains neutral with regard to jurisdictional claims in published maps and institutional affiliations. 